\title{
Drying protocol influence on the bond strength and apical sealing of three different endodontic sealers
}

\begin{abstract}
Adrianne Calixto Freire de PAULA ${ }^{(a)}$ Manoel BRITO-JÚNIOR(a) Carla Cristina Camilo ARAÚJO(a) Manoel Damião SOUSA-NETO(b) Antonio Miranda da CRUZ-FILHO(b)
\end{abstract}

(a) Universidade Estadual de Montes Claros - Unimontes, School of Dentistry, Interinstitutional PhD Program, Montes Claros, MG, Brazil.

(b) Universidade de São Paulo - USP, School of Dentistry, Department of Restorative Dentistry, Ribeirão Preto, SP, Brazil.

Declaration of Interests: The authors certify that they have no commercial or associative interest that represents a conflict of interest in connection with the manuscript.

Corresponding Author: Adrianne Calixto Freire de Paula E-mail:adriannepaula@usp.br

DOI: 10.1590/1807-3107BOR-2016.vol30.0050

Submitted: Aug 05, 2015

Accepted for publication: Nov 22, 2015

Last revision: Feb 23, 2016
Abstract: The aim of this study was to evaluate the influence of drying protocols (DP) on the apical sealing (AS) and on the bond strength (BS) of teeth filled with different sealers. The root canals of one hundred and fifty-six roots of maxillary canines were prepared with Reciproc rotary files (R50). The teeth were randomly divided into four groups $(n=39)$, according to the DP: GI-paper points; GII-70\% isopropyl alcohol + aspiration with NaviTip points; GIII-95\% ethanol + paper points; GIV-EndoVac + paper points. Each group was divided into subgroups, according to the sealer used: AH Plus, Sealapex and MTA Fillapex, using a single-cone technique. Evaluation of AS and BS was performed with fluid filtration (FF) and push-out (PO) methods, respectively. The PO test consisted of sectioning the roots, and subjecting a single slice from each third to testing and analysis for failure type. The data was submitted to two-way and three-way variance analysis (ANOVA) and Tukey $(\alpha=5 \%)$. The AS showed no drying protocol influence. The FF results revealed a statistically significant difference between MTA and Sealapex $(p<0.05)$ sealers. The BS test values showed that there was no statistical significant difference among the canal thirds $(\mathrm{p}>0.05)$, but that there was such a difference among the sealers $(p<0.05)$, among the protocols $(p<0.05)$, and in the interaction between sealers and protocols $(p<0.05)$. AH Plus revealed the highest BS values among the sealers; the highest BS results for the sealers occurred with the specimens used with isopropyl alcohol, compared with ethanol and EndoVac.

Keywords: Root Canal Therapy; Wettability; Adhesivenes.

\section{Introduction}

Root canal sealers are primarily classified as resin, zinc oxideeugenolbased, glass-ionomer, and calcium hydroxide. Those containing calcium hydroxide, such as Sealape ${ }^{\circledast}$, were devised with the intention of combining the physical and chemical properties of the sealer with the biological properties of calcium hydroxide. ${ }^{1} \mathrm{AH}$ Plus ${ }^{\circledR}$ epoxy resin sealer has been used in research as a control, ${ }^{2}$ due to its dimensional stability, ${ }^{3}$ microretention to dentin and reduced solubility., ${ }^{4,2}$ Special attention has been given by researchers to certain newly introduced sealers on the market, such as MTA Fillapex ${ }^{\circledast}$. This material differs from conventional MTA, which contains calcium silicate. It was proposed for reducing the working time of the MTA, facilitating the manipulation phase, ${ }^{5}$ and improving adhesion strength. ${ }^{6}$ 
The literature has drawn attention to the importance of the adhesive properties of root canal sealers. ${ }^{7,9}, 9$ If a material bonds to the root canal walls, it resists dislodgment of the filling. ${ }^{9}$ Adhesion capacity can be influenced by the drying protocol (DP) of the root canal, which interferes in the microleakage process. ${ }^{10,11}$ Although absorbent paper points are normally employed for drying, isopropyl alcohol has provided fillings with high bond strength (BS). ${ }^{2}$ At the same time, mechanical devices such as the EndoVac ${ }^{\circledR}$ also allow drying of the root canal; however, there are still no reports on its performance.

The push-out (PO) test provided information that enabled better understanding of the BS of root canal sealers. ${ }^{12,13}$ This method has been used and recommended in the current literature. ${ }^{14}$ Fluid filtration (FF) is a method used to determine the sealing ability of the filling materials, and offers advantages such as: preserving the samples after testing, ${ }^{15,16}$ providing quantitative and volumetric data, ${ }^{17}$ and adjusting the sensitivity of the fluid transport system..$^{15}$ The method has proved accurate and reproducible. ${ }^{16}$

This study examined the influence of different DPs of the root canal on the apical sealing (AS) and BS of epoxy resin-based sealers (AH Plus ${ }^{\circledR}$ ), with calcium hydroxide (Sealapex ${ }^{\circledR}$ ) and calcium silicate (MTA Fillapex ${ }^{\circledR}$ ), based on FF and PO tests. The null hypothesis tested was that different drying protocols of the root canal would not affect the apical sealing and bond strength of calcium hydroxide-based and epoxy resin-based sealers.

\section{Methodology}

\section{Sample selection}

After approval of this study by the local Ethics and Research Committee (protocol no. 250.960), 156 human maxillary canine teeth were selected. They were selected by means of a stereomicroscope (25x), and included those with the apical foramen located in the apical vertex and having rounded shapes, and with similar characteristics. The roots were transversely sectioned in the cervical region, standardizing the length at 15 millimeters.

\section{Biomechanical preparation}

The working length (WL) was established by inserting a \#15 K-file (Dentsply Maillefer, Ballaigues, Switzerland) in the root canal, until its tip was visualized in the apical foramen, and then retracting it 1 millimeter. The Reciproc ${ }^{\circledR}$ system (VDW-Silver, Munich, Germany) was used for instrumentation, with a \#R50 file, and irrigation with 1\% sodium hypochlorite. Afterwards, the canals were flooded with $5 \mathrm{~mL}$ of $17 \%$ EDTA for $3 \mathrm{~min}$, followed by irrigation with $5 \mathrm{~mL}$ of distilled water.

\section{Distribution of groups}

The roots were randomly distributed into 4 groups, according to the DP ( $\mathrm{n}=39)$ : GI-absorbent paper points; GII- 70\% isopropyl alcohol + aspiration with NaviTip points; GIII-95\% ethanol + paper points; GIV-EndoVac ${ }^{\circledR}+$ paper points. In GI, \#50 paper points (Tanari, Manacapuru, Brazil) were successively inserted into the root canal, until the last one to be removed came out completely dry. In GII, $1 \mathrm{~mL}$ of $70 \%$ isopropyl alcohol was inserted into the root canal, with a 30-guage blunt-tip syringe as close to the WL as possible. The solution was left in for $1 \mathrm{~min}$, and then aspirated with NaviTip points (Ultradent, South Jordan, USA) for 5 seconds. In GIII, paper points were initially used to remove the distilled water excess, similar to GI. Afterwards, the root canal was flooded with $95 \%$ ethanol, by inserting a blunt-tip syringe as close to the $\mathrm{WL}$ as possible. The solution was left in for $10 \mathrm{~s}$, and was dried immediately thereafter with paper points. The following procedure was used for GIV-EndoVac ${ }^{\circledast}$ (SybronEndo, Orange, USA): a macrocannula was introduced into the canal, at maximum depth in the apical direction, if no resistance was encountered. Then, a microcannula was placed at the WL, and, lastly, a single-cone paper point completed the drying process.

Each group was divided into 3 subgroups, according to the sealer used: AH Plus ${ }^{\circledR}$ (De Trey-Dentsply, Konstanz, Germany); Sealapex ${ }^{\circledR}$ (Kerr-Sybron, Orange, USA); and MTA Fillapex ${ }^{\circledR}$ (Angelus Ind. Prod. Odontológicos, Londrina, Brazil). The sealers were handled according to the guidelines set by their respective manufacturers. The roots were filled using the single-cone technique, and stored 
in an incubator at $37^{\circ} \mathrm{C}$ with $95 \%$ humidity, for a period corresponding to three times the hardening time of the respective sealers. Eight of the thirteen roots belonging to each subgroup served to assess the AS, and five, to test the BS, using the FF and PO methods, respectively.

\section{Fluid filtration method}

The roots were covered with two coats of clear enamel and a cyanoacrylate ester (Henkel Ltd., Itapevi, Brazil), except for the apical millimeter and the upper inner surface of the cervical portion. Then, a Cralplast universal type 0-200 mL tip (Cral Artigos para Laboratório Ltda., Cotia, Brazil) was inserted into the apical root portion, and the root/tip interface was sealed with the same coating materials. The root assembly/plastic tubing was connected to the FF system, filled with distilled water, and submitted to a pressure of $10 \mathrm{psi}$. The measurement of the infiltrated volume of fluid inside the root was expressed as $\mu \mathrm{L} /$ minutes.

\section{Push-out test}

Initially, the roots were sectioned transversely by a cutting machine (Isomet 1000, Buehler, Illinois, USA), yielding 6 slices, each with a thickness of 2.0 millimeters. The first and last slices were discarded, and each second third was selected for testing. The Instron 4444 Universal Testing Machine was used (Instron Corporation, Canton, USA) with a speed of $1 \mathrm{~mm} /$ minutes. The force required for the displacement of the filling material, in kilonewtons $(\mathrm{kN})$, was transformed into stress $(\sigma)$ given in megapascals $(\mathrm{MPa})$, by dividing the value of the force $(\mathrm{F})$ of displacement by the adhesion area of the filling material (SL) in $\mathrm{mm}^{2}$. The following formula was used to calculate the approximate value of the area: $\mathrm{SL}=\pi$ $(\mathrm{R}+\mathrm{r}) \mathrm{g}$, where: $\mathrm{SL}=$ adhesion area of sealer; $\pi=3.14$; $\mathrm{R}=$ radius of the coronal portion of the slice, in $\mathrm{mm}$; $\mathrm{r}=$ radius of the apical portion of the slice, in $\mathrm{mm}$; $\mathrm{g}=$ relative height of the slice, in $\mathrm{mm}$. After testing the slices, an analysis was made of the failure type displayed by each slice, using a stereomicroscope (25x) (Zeiss, Stemi 2000-C, Jena, Germany). The failures were classified according to a study by Saleh et al., ${ }^{18}$ namely, adhesive to dentin, when the filling material was detached from the dentin; adhesive to filling material, when the gutta-percha was detached from the root canal sealer; mixed, when the sealer became detached from both the dentin and gutta-percha; cohesive to dentin, when there was a fracture in the dentin; and cohesive to filling material, when there was a fracture in the root canal sealer.

\section{Statistical analysis}

The FF and BS data were subjected to the two-way ANOVA test, and the three-way ANOVA with a split plot, respectively, followed by the Tukey complementary test $(\alpha=0.05 \%)$.

\section{Results}

\section{Fluid filtration analysis}

Only the root canal sealers showed a significantly statistical difference $(p=0.029)$ (Table 1$)$. No difference was observed among the DPs $(p=0.494)$, or in the interaction between sealer and protocol $(p=0.340)$. The Tukey test (Table 2) showed a significant difference only between MTA Fillapex and Sealapex sealers $(p=0.048)$, and a similarity between AH Plus and MTA Fillapex ( $p=0.993)$, and between AH Plus and Sealapex $(p=0.063)$.

\section{Push-out analysis}

The three-way ANOVA test with a split plot showed no statistically significant difference among the root canal thirds $(p=0.316)$, or interactions among sealers/thirds $(p=0.630)$ and protocols/thirds $(p=0.888)$. There were significant differences among the three different sealer fillings ( $p<0.001)$, among the four different DPs $(p=0.001)$, and in the interaction between sealers and protocols $(p=0.001)$.

Based on the Tukey test, AH Plus $(1.39 \pm 0.60)$ $(\mathrm{p}<001)$ was identified as presenting the highest BS values, as compared with Sealapex $(0.83 \pm 0.33)$ and MTA Fillapex $(0.76 \pm 0.34)$, with no difference between the last two $(p=0.578)$. Among the protocols, isopropyl alcohol $(1.19 \pm 0.58)$ promoted BS values similar to the paper points $(1.04 \pm 0.55)(p=0.358)$. However, isopropyl alcohol was statistically different from ethanol $(0.89 \pm 0.35)(p=0.005)$ and EndoVac $(0.86 \pm 0.53)(p=0.002)$, with no significant difference 
Table 1. Analysis of variance test.

\begin{tabular}{lccccc}
\hline Source of variation & SS & DF & MS & $F$ & P \\
\hline Sealers & 0.255 & 2 & 0.127 & 3.679 & 0.029 \\
Protocols & 0.0837 & 3 & 0.0279 & 0.806 & 0.494 \\
Sealers vs. Protocols & 0.239 & 6 & 0.0399 & 1.152 & 0.340 \\
Residual & 2.910 & 84 & 0.0346 & - & - \\
Total & 3.488 & 95 & 0.0367 & - & - \\
\hline
\end{tabular}

SS: sum of square; DF: degrees of freedom; MS: mean square; F: F-statistics. p: significance level.

Table 2. Tukey test.

\begin{tabular}{lcc}
\hline Sealer & Difference in Means & $\mathrm{q}$ \\
\hline MTA vs. Sealapex & $0.112^{*}$ & $3.400^{*}$ \\
MTA vs. AH Plus & $0.00531^{* *}$ & $0.161^{* *}$ \\
AH Plus vs. Sealapex & $0.107^{* *}$ & $3.239^{* *}$ \\
\hline $\mathrm{q}: \mathrm{q}$ test statistic. & & \\
${ }^{*} \mathrm{p}<0.05$ & & \\
${ }^{* *} \mathrm{~ns}=$ not significance & &
\end{tabular}

between these last two $(p=0.991)$. The paper point protocol was similar to that of ethanol $(p=0.320)$ and of EndoVac $(p=0.190)$. Since there was no statistical difference among the root canal thirds (cervical, middle, and apical), and since this variance factor neither influenced the DP nor the sealers, a table was constructed with the BS mean values of the three root thirds, according to the sealers and the DP (Table 3).

In the sealer/protocol interaction, it was found that specimens filled with AH Plus sealer and dried with isopropyl alcohol showed higher BS, in comparison with the groups dried with ethanol $(\mathrm{p}<0.001)$ and EndoVac $(\mathrm{p}=0.001)$. Sealapex sealer did not undergo any interference from the DP. In the canals filled with MTA Fillapex and dried with isopropyl alcohol, the BS was significantly higher than those dried with EndoVac.

\section{Fracture pattern analysis}

Table 4 shows the incidence (\%) of the failures types that occurred after the PO test for each root third.

\section{Discussion}

In the present study, the drying protocols did not affect the apical sealing; therefore, the null hypothesis was confirmed. The leakage observed in specimens filled with AH Plus was similar to that observed in the fillings with Sealapex and MTA Fillapex. Xu et al. ${ }^{19}$ and Sagsen et al. ${ }^{20}$ reported similar results. However, a previous study reported lower leakage values in specimens filled with Sealapex, compared with AH Plus, after 15 days of sealing. ${ }^{16}$ Nevertheless, a progressive increase in leakage was noted in the Sealapex group, over the course of this experiment, and the results for both sealers were similar at the end of 60 days. Sealapex underwent volumetric expansion because of water absorption during hardening. This expansion may cause an increase in solubility, with a consequent effect on sealing capability. ${ }^{21}$ The discrepancy in the results may be attributed to the difference in the methods used. Even when similar methods are adopted, the individual parameters of each method must be considered. The measurement period of the leakage, the hardening time of the sealer, and the pressure applied to the system may all influence the results. ${ }^{22,17}$

There was similarity in the BS among the three root thirds. A previous study reported that even if tubule density is different throughout the root thirds, this factor is not enough to interfere with adhesion of the root canal sealer. ${ }^{23}$

The null hypothesis was rejected, because the drying protocols affected the push-out bond strength differently. AH Plus presented the highest BS values, corroborating previous research findings. ${ }^{24,2}$ Several characteristics of this material promote its greater adhesion capability, in relation to Sealapex and MTA Fillapex. AH Plus is an epoxy resin-based sealer with high polymerization time and good flow capacity. ${ }^{25}$ These characteristics favor its penetration through the dentinal tubules, ${ }^{26}$ forming tags, similar to what occurs with dentin adhesions..$^{27,28,13}$ Moreover, 
Table 3. Mean \pm SD of the BS of the three thirds according to sealer and protocol used.

\begin{tabular}{|c|c|c|c|c|}
\hline \multirow{2}{*}{ Protocol } & \multicolumn{3}{|c|}{ Sealer } & \multirow{2}{*}{ Pooled Average } \\
\hline & AH Plus & Sealapex & MTA & \\
\hline Isopropyl & $1.80 \pm 0.49$ & $0.82 \pm 0.30$ & $0.93 \pm 0.36$ & $1.19 \pm 0.58^{\mathrm{A}}$ \\
\hline Paper point & $1.53 \pm 0.61$ & $0.78 \pm 0.27$ & $0.81 \pm 0.35$ & $1.04 \pm 0.55^{\mathrm{AB}}$ \\
\hline EndoVac & $1.25 \pm 0.60$ & $0.83 \pm 0.45$ & $0.51 \pm 0.22$ & $0.86 \pm 0.53^{B}$ \\
\hline \multirow{2}{*}{ Ethanol } & $0.98 \pm 0.40$ & $0.90 \pm 0.31$ & $0.78 \pm 0.32$ & $0.89 \pm 0.35^{B}$ \\
\hline & $1.39 \pm 0.60^{A}$ & $0.83 \pm 0.33^{\mathrm{B}}$ & $0.76 \pm 0.34^{B}$ & - \\
\hline
\end{tabular}

Different superscript capital letters in the same column or the same line represent a statistically significant difference (SD) among the groups ( $p<.01)$.

Table 4. Frequency of failure types (\%) by root thirds.

\begin{tabular}{lccc}
\hline \multirow{2}{*}{ Type of Failure } & \multicolumn{3}{c}{ Canal Third } \\
\cline { 2 - 4 } & Cervical & Middle & Apical \\
\hline Cohesive to filling material & 50 & 23.33 & 8.75 \\
Cohesive to dentin & 10 & 16.66 & 12.10 \\
Adhesive to dentin & 10 & 1.67 & 32.50 \\
Adhesive to filling material & - & 1.67 & 1.65 \\
Mixed & 30 & 56.67 & 45 \\
\hline
\end{tabular}

a previous study has suggested that the adhesion of AH Plus to dentin is due not only to mechanical overlapping, but also to its potential to chemically bind to the collagen matrix of the dentin tissue. ${ }^{29}$

The BS was influenced by the DP, as well as the sealer/protocol interaction. These results are consistent with the findings described in the current literature. Research showed that the moist conditions of the root canal directly interfere in the BS of root canal sealers. ${ }^{11,2}$ Therefore, neither completely moist nor completely dry canals favor adhesion to the sealer. ${ }^{10,11}$

Regarding the influence of the DP in relation to the BS of the materials, specimens dried with isopropyl alcohol showed the highest BS values, compared with ethanol and EndoVac. Whereas the most favorable conditions for obtaining adhesion to the sealer was a root surface that was not completely dehydrated, it is believed that because ethanol $\left(\mathrm{C}_{2} \mathrm{H}_{5} \mathrm{OH}\right)$ presents a molecule with higher polarity, this could have favored greater water removal from dentinal tubules than isopropyl alcohol $\left(\mathrm{C}_{3} \mathrm{H}_{7} \mathrm{OH}\right)$, with lower polarity. ${ }^{30,10}$ The results for the isopropyl alcohol group were similar to those of the absorbent paper point group; this suggests that the paper point promoted the drying of the canal, but not fully, thus retaining the moisture of the root dentin. The protocol/material interaction analysis showed that the use of paper points with AH Plus presented significantly higher BS values than Sealapex and MTA Fillapex with paper points, thus confirming the previous finding.

The BS values for Sealapex and MTA Fillapex were similar and significantly lower than those for AH Plus, in the specimens dried with isopropyl alcohol, paper points and EndoVac. Although the EndoVac system presents an interesting hydraulic drive, its dynamic as a drying system was not effective. Drying with one of the three previous groups probably retained excessive moisture within the canal, impairing adhesion of Sealapex and MTA Fillapex. This behavior can mostly likely be explained by these cements not having the hydrophilic characteristics displayed by AH Plus.

The analysis of the specimens showed that cohesive failures occurred in the cervical third, primarily in the cohesive material, regardless of the protocol or sealer used. This type of failure may be attributed to the greater amount of sealer in that region, depending on the adopted filling technique, according which a greater open area was noticed between the dentin and the gutta-percha cone in the cervical region than in the remaining thirds.

The results of this study revealed the importance of obtaining more information on DP, in regard to moist conditions, type of sealer favoring adhesion, and curbing of apical leakage.

\section{Conclusion}

Under the conditions of this study, DP did not influence the AS of the tested root canal sealers. 
However, the highest BS values were observed in specimens dried with isopropyl alcohol, compared with ethanol and EndoVac.

\section{References}

1. Costa CCR, Rocha VGN, Habitante SM, Raldi DP, Lage-Marques JL. Análise da infiltração apical de um novo cimento endodôntico a base de MTA. Cienc Odontol Bras. 2009; 12(2):35-40.

2. Dias KC, Soares CJ, Steier L, Versiani MA, Rached-Júnior FJA, Pécora JD, et al. Influence of drying protocol with isopropyl alcohol on the bond strength of resin-based sealers to the root dentin. J Endod. 2014;40(9):1454-8. doi:10.1016/j.joen.2014.02.021

3. Eldeniz AU, Mustafa K, Ørstavik D, Dahl JE. Cytotoxicity of new resin-, calcium hydroxide- and silicone-based root canal sealers on fibroblasts derived from human gingiva and L929 cell lines. Int Endod J. 2007;40(5):329-37. doi:10.1111/j.1365-2591.2007.01211.x

4. Carneiro SMBS, Sousa-Neto MD, Rached-Júnior FJA, Miranda CES, Silva SRC, Silva-Sousa YTC. Push-out strength of root fillings with or without thermomechanical compaction. Int Endod J. 2012;45(9):821-8. doi:10.1111/j.1365-2591.2012.02039.x

5. Parirokh M, Torabinejad M. Mineral trioxide aggregate: a comprehensive literature review - Part I: chemical, physical, and antibacterial proprieties. J Endod. 2010;36(1): 16-27. doi:10.1016/j.joen.2009.09.006

6. Camilleri J. Evaluation of selected properties of mineral trioxide aggregate sealer cement. J Endod. 2009;35(10):1412-7. doi:10.1016/j.joen.2009.07.008

7. Lee KW, Williams MC, Camps JJ, Pashley DH. Adhesion of endodontic sealers to dentin and gutta-percha. J Endod. 2002;28(10):684-8. doi:10.1097/00004770-200210000-00002

8. Gogos C, Stavrianos C, Kolokouris I, Papadoyannis I, Economides N. Shear bond strength of AH-26 root canal sealer to dentine using three dentine bonding agents. J Dent. 2003;31(5):321-6. doi:10.1016/S0300-5712(03)00064-2

9. Sagsen B, Ustün Y, Demirbuga S, Pala K. Push-out bond strength of two new calcium silicate-based endodontic sealers to root canal dentine. Int Endod J. 2011;44(12):1088-91. doi:10.1111/j.1365-2591.2011.01925.x

10. Zmener O, Pameijer $\mathrm{CH}$, Serrano AS, Vidueira M, Macchi RL. Significance of moist root canal dentin with the use of methacrylate-based endodontic sealers: an in vitro coronal dye leakage study. J Endod. 2008;34(1):76-9. doi:10.1016/j.joen.2007.10.012

11. Nagas E, Uyanik MO, Eymirli A, Cehreli ZC, Vallittu PK, Lassila LVJ, et al. Dentin moisture conditions affect the adhesion of root canal sealers. J Endod. 2012;38(2):240-4. doi:10.1016/j.joen.2011.09.027

\section{Acknowledgments}

The authors wish to thank Fundação de Amparo à Pesquisa de Minas Gerais -FAPEMIG for funding this study.

12. Sousa-Neto MD, Coelho FIS, Marchesan MA, Alfredo E, Silva-Sousa YTC. Ex vivo study of the adhesion of an epoxy-based sealer to human dentine submitted to irradiation with Er: YAG and Nd: YAG. Int Endod J. 2005;38(12):866-70. doi:10.1111/j.1365-2591.2005.01027.x

13. Costa JA, Rached-Júnior FJA, Souza-Gabriel AE, Silva-Sousa YTC, Sousa-Neto MD. Push-out strength of methacrylate resin-based sealers to root canal walls. Int Endod J. 2010;43(8):698-706. doi:10.1111/j.1365-2591.2010.01766.x

14. Topçuoğlu HS, Tuncay Ö, Demirbuga S, Dinçer NA, Arslan $\mathrm{H}$. The effect of different final irrigant activation techniques on the bond strength of an epoxy resin-based endodontic sealer: a preliminary study. J Endod. 2014;40(6):862-866. doi:10.1016/j.joen.2013.10.012

15. Zhang W, Li Z, Peng B. Assessment of a new root canal sealer's apical sealing ability. Oral Surg Oral Med Oral Pathol Oral Radiol Endod. 2009;107(6):e79-82. doi:10.1016/j.tripleo.2009.02.024

16. Vasconcelos BC, Bernardes RA, Duarte MAH, Bramante CM, Moraes IG. Apical sealing of root canal fillings performed with five different endodontic sealers: analysis by fluid filtration. J Appl Oral Sci. 2011;19(4):324-8. doi:10.1590/S1678-77572011005000005

17. Yilmaz Z, Tuncel B, Ozdemir HO, Serper A. Microleakage evaluation of roots filled with different obturation techniques and sealers. Oral Surg Oral Med Oral Pathol Oral Radiol Endod. 2009;108(1):124-8. doi:10.1016/j.tripleo.2009.03.010

18. Saleh IM, Ruyter IE, Haapasalo MP, Ørstavik D. Adhesion of endodontic sealers: scanning electron microscopy and energy dispersive spectroscopy. J Endod. 2003;29(9):595-601. doi:10.1097/00004770-200309000-00013

19. Xu Q, Fan M-w, Fan B, Cheung GSP, Hu H-l. A new quantitative method using glucose for analysis of endodontic leakage. Oral Surg Oral Med Oral Pathol Oral Radiol Endod. 2005;99(1):107-11. doi:10.1016/j.tripleo.2004.06.006

20. Sagsen B, Er O, Kahraman Y, Orucoglu H. Evaluation of microleakage of roots filled with different techniques with a computerized fluid filtration technique. J Endod. 2006;32(12):1168-70. doi:10.1016/j.joen.2006.07.016

21. Caicedo R, von Fraunhofer JA. The properties of endodontic sealer cements. J Endod. 1988;14(11):527-34. doi:10.1016/S0099-2399(88)80084-0

22. Silva-Neto UX, Moraes IG, Westphalen VPD, Menezes R, Carneiro E, Fariniuk LF. Leakage of 4 resin-based root-canal sealers used with a single-cone technique. Oral Surg Oral 
Med Oral Pathol Oral Radiol Endod. 2007;104(2):e53-7. doi:10.1016/j.tripleo.2007.02.007

23. Babb BR, Loushine RJ, Bryan TE, Ames JN, Causey MS, Kim J, et al. bonding of self-adhesive (self-etching) root canal sealers to radicular dentin. J Endod. 2009;35(4):578-82. doi:10.1016/j.joen.2009.01.005

24. De-Deus G, Di Giorgi K, Fidel S, Fidel RAS, Paciornik S. Push-out bond strength of Resilon/Epiphany and Resilon/Epiphany self-etch to root dentin. J Endod. 2009;35(7):1048-50. doi:10.1016/j.joen.2009.04.024

25. Versiani MA, Carvalho-Junior JR, Padilha MI, Lacey S, Pascon EA, Sousa-Neto MD. A comparative study of physicochemical properties of AH Plus and Epiphany root canal sealants. Int Endod J. 2006;39(6):464-71. doi:10.1111/j.1365-2591.2006.01105.x

26. Vilanova WV, Carvalho-Junior JR, Alfredo E, Sousa-Neto MD, Silva-Sousa YTC. Effect of intracanal irrigants on the bond strength of epoxy resin-based and methacrylate resin-based sealers to root canal walls. Int Endod J. 2012;45(1):42-48. doi:10.1111/j.1365-2591.2011.01945.x
27. Sousa-Neto MD, Passarinho-Neto JG, Carvalho-Junior JR, Cruz-Filho AM, Pécora JD, Saquy PC. Evaluation of the effect of EDTA, EGTA and CDTA on dentin adhesiveness and microleakage with different root canal sealers. Braz Dent J. 2002;13(2):123-8. doi:10.1590/S0103-64402002000200009

28. Rached-Júnior FJA, Souza-Gabriel AE, Alfredo E, Miranda CES, Silva-Sousa YTC, Sousa-Neto MD. Bond strength of Epiphany sealer prepared with resinous solvent. J Endod. 2009 ;35(2):251-5. doi:10.1016/j.joen.2008.10.027

29. Fisher MA, Berzins DW, Bahcall JK. An in vitro comparison of bond strength of various obturation materials to root canal dentin using a push-out test design. J Endod. 2007;33(7):856-8. doi:10.1016/j.joen.2007.02.011

30. Engel GT, Goodell GG, McClanahan SB. Sealer penetration and apical microleakeage in smear-free dentin after a final rinse with either 70\% isopropyl alcohol or peridex. J Endod. 2005;31(8):620-3. doi:10.1097/01.don.0000152296.06840.14 